\title{
Design \& embalagens: um estudo de caso da indústria Itálica
}

Luis Eduardo de Souza (Currículo Lattes) Marli Teresinha Everling (Currículo Lattes)

\section{INTRODUÇÃO}

A microindústria de alimentos congelados para a qual se realizou este estudo está situada em Joinville/SC, foi fundada em setembro de 1993 e atua há mais de vinte anos na produção e comercialização de massas alimentícias e molhos congelados. Caracterizada como uma pequena indústria familiar, é conduzida pelo casal de sóciosproprietários e produz, de forma caseira, uma média de três mil quilos de alimento por mês.

A empresa conta atualmente com 30 pontos de venda (distribuídos entre cidades de Santa Catarina e na cidade de Curitiba/ 
PR) e tem um portfólio composto por vinte produtos, divididos nas Ilinhas: (1) de produtos que vão direto ao forno, (2) de produtos que recebem molho e vão ao forno e (3) de molhos prontos. A Figura 1 descreve quais produtos compõem as linhas de produtos existentes.

Figura 1 - Linha de produtos

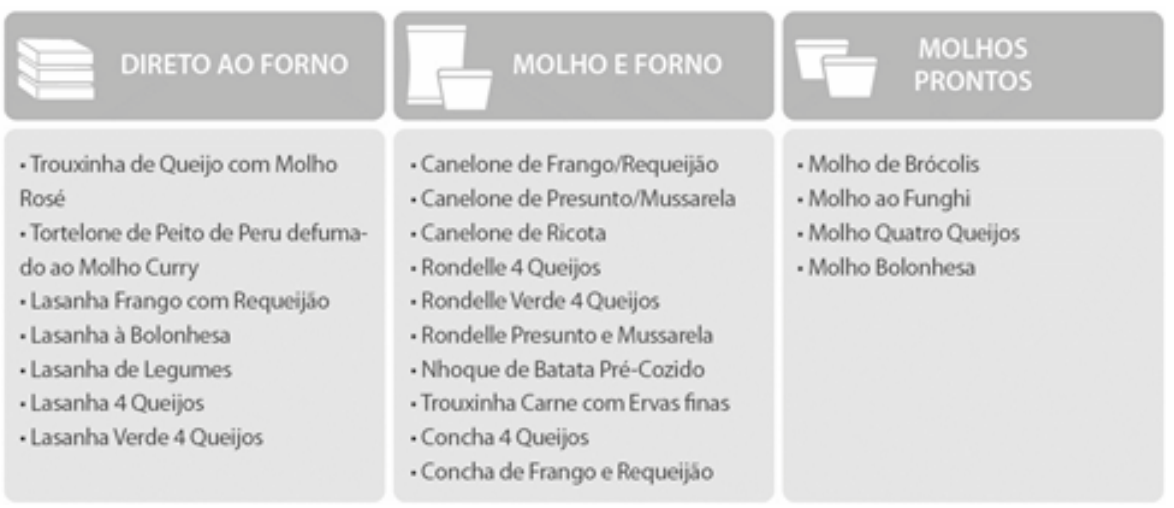

Fonte: arquivo pessoal

A sócia-proprietária da indústria relatou que a última atualização das embalagens se deu em 2007 e foi direcionada apenas na linha Direto ao Forno, sendo que as demais embalagens não são atualizadas desde 2004.

A etapa da pesquisa aqui relatada visou o mapeamento de problemas associados a Relações de Uso, Design Centrado no Usuário (DCU) e Design de Informação, com foco no uso das embalagens da indústria em questão. Já o procedimento utilizado consistiu uma experiência imersiva ${ }^{1}$ de uso. Como parte do processo de investigação os autores da pesquisa (e designer) realizou a experiência do uso de dois de seus produtos, com o intuito de ampliar a percepção acerca

\footnotetext{
${ }^{1}$ Para a experiência imersiva de uso, foi realizado um estudo em que considerou todo o processo de consumo do produto, desde a compra no supermercado, passando pelo manuseio das embalagens, preparo dos alimentos, até o descarte dos resíduos.
} 
de problemas e traçar recomendações preliminares no intuito de possibilitar o aprofundamento das etapas de pesquisa com outros usuários. A abordagem partiu da premissa que a negligência de aspectos relacionados ao uso de embalagens (ou de configurações que sugerem o uso indevido), associados às funcionalidades deficientes e comunicação visual falha, podem ocasionar problemas como desperdício do produto e uso inadequado.

\section{RELAÇÕES DE USO E USABILIDADE}

O termo Relações de uso diz respeito à usabilidade, ou seja, de que forma se dá o relacionamento do usuário com algum produto, sistema ou serviço. Preece et al. (2013, p. 18) afirmam que pela perspectiva do usuário "usabilidade visa assegurar que produtos interativos sejam fáceis de aprender a usar, eficazes e agradáveis".

Todo produto ao ser utilizado gera uma relação de uso entre o objeto e o usuário, e cabe ao desenvolvedor do produto otimizar as interações permitindo ao usuário realizar suas atividades de forma plena e segura. Segundo Preece et al. (2013, p. 18), a usabilidade é dividida nas seguintes metas: ser eficaz no uso (eficácia); ser eficiente no uso (eficiência); ser segura no uso (segurança); ter boa utilidade (utilidade); ser fácil de aprender (learnability); ser fácil de lembrar como usar (memorability). Para os autores tais metas podem ser utilizadas em forma perguntas, tendo o objetivo de fornecer ao designer possibilidades de avaliar os aspectos de um produto e a experiência de uso.

Com o objetivo de definir critérios para o projeto de embalagem, buscou-se categorizar aspectos relacionados a relações de uso; para tal foram utilizados os princípios de usabilidade sob a ótica do design. Esses princípios foram propostos por Preece et al. (2013) e ampliam a 
perspectiva proposta, inicialmente, por Norman (2006) em seu livro O Design do dia a dia. Para Preece et al. (2013, p. 25), “os princípios de Design são derivados de uma mistura de conhecimento baseado em teoria, experiência e bom senso".

A partir dos princípios propostos por Norman e Preece et al. (visibilidade, feedback, restrições, mapeamento, consistência e affordance), suas definições são apresentados na Figura 2 a seguir.

Figura 2 - Princípios de design

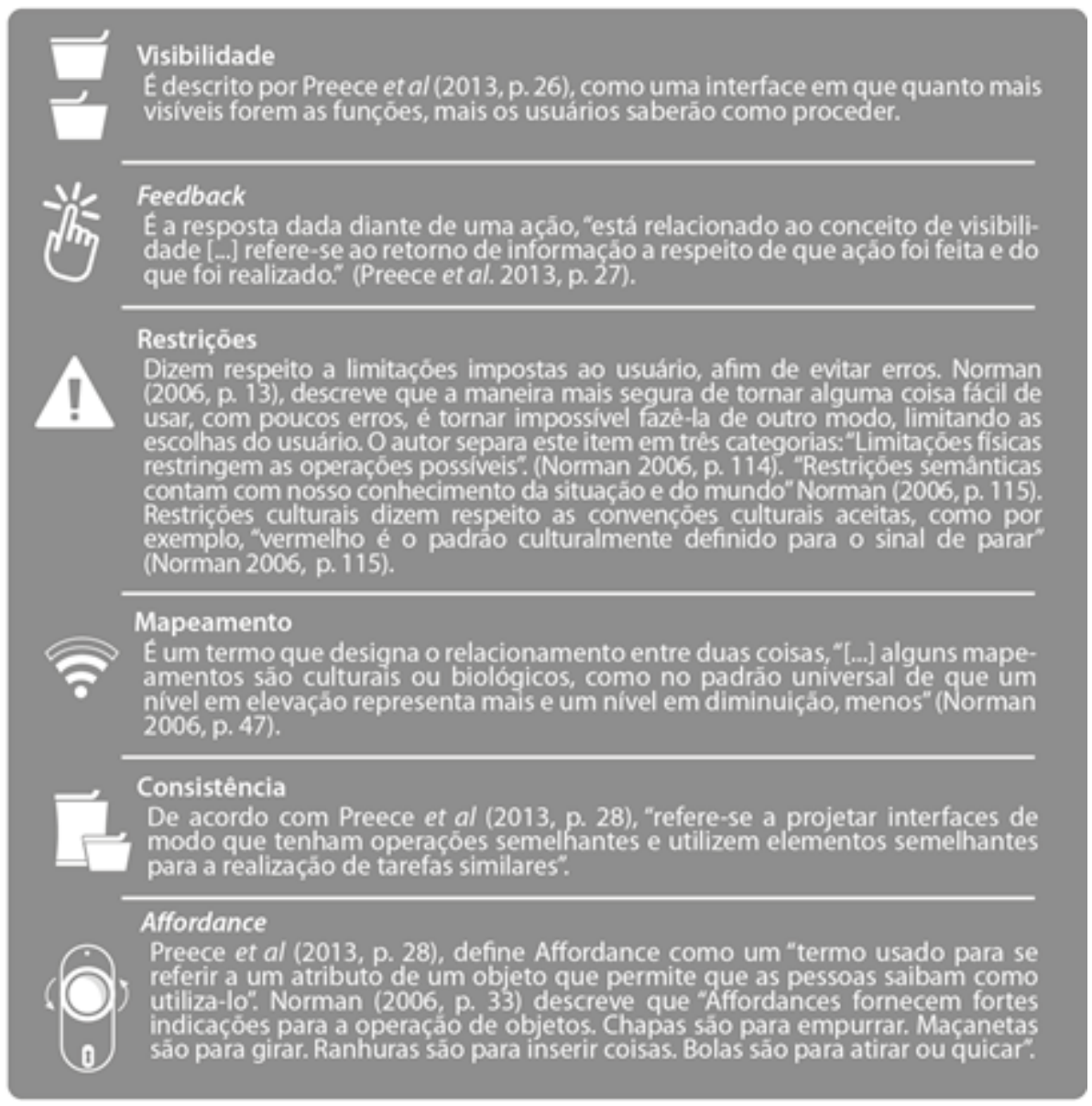

Fonte: baseada em Preece et al. (2013) e Norman (2006) 
Ao Aplicar esses conceitos a um projeto de embalagens, é possível avaliar diversos aspectos, como, por exemplo: quão eficiente e eficaz é a embalagem em relação ao uso? Quão seguro é o uso dela? O quão eficiente é sua comunicação e seu formato? O quão útil é seu propósito? Qual o nível de dificuldade em entender rapidamente sua utilização? E, por último, qual o nível de dificuldade existente em lembrar como utilizá-la?

Além dos aspectos anteriormente citados, ao mapear as relações de uso possíveis ou existentes em determinada situação, deve-se atentar para questões do entorno, como: avaliar o uso intuitivo da embalagem (de modo direto e instantâneo, sem auxílio de regras), uso prescrito (usos previstos pelo desenvolvedor) versus o uso real (usos reais que podem ser diferentes do prescrito) e variedade de interações ao longo do ciclo de vida (que considera questões além da usabilidade, como transporte, manutenção, pós-venda etc.).

\section{DESIGN INFORMACIONAL}

Design informacional está relacionado à apresentação e representação de informações de uma forma visual. Para este projeto de embalagem, optou-se por abordar esse tema com o objetivo de categorizar problemas percebidos em relação à visibilidade, legibilidade, compreensibilidade de signos visuais, problemas de percepção, decodificação, navegação e aprendizagem em relação à comunicação da embalagem.

Para a categorização dos problemas informacionais da embalagens, foram utilizados os critérios informacionais/ visuais e cognitivos propostos por Moraes e Mont'alvão (2009) e recomendações de representação da informação visual propostas por Mijksenaar e Westendorp (1999) no livro Open Here. 
De acordo com Moraes e Mont'alvão (2009, p. 131), problemas informacionais e visuais dizem respeito a "deficiências na detecção, discriminação e identificação de informações em telas, painéis, mostradores e placas de sinalização, resultantes da má visibilidade, legibilidade e compreensibilidade de signos visuais, com prejuízos para a percepção e para a tomada de decisões". Já problemas cognitivos, segundo as autoras, dizem respeito à:

dificuldade de decodificação, aprendizagem, memorização em face de inconsistências lógicas e de navegação dos subsistemas comunicacionais e dialogais, que resultam em perturbações para a seleção de informações, para as estratégias cognoscitivas, para a resolução de problemas e para a tomada de decisões (IBID).

Esses critérios podem contribuir para um projeto de embalagem de alimento em que há informações variadas, tais quais modo preparo, uso correto do produto, características do produto, modo de conservação, prazo de validade, restrições de uso, sugestões de preparo, entre outras.

Mijksenaar e Westendorp (1999) contribuem com o estabelecimento de critérios que podem orientar a representação de informações visuais ampliando a eficácia da comunicação; buscouse esse referencial no intuito de considerar cuidados que o designer deve tomar ao planejar instruções visuais para as embalagens; o esquema chamado de Elementos Engenhosos, proposto pelos autores, é apresentado na Figura 3 a seguir. 
Figura 3 - Elementos engenhosos

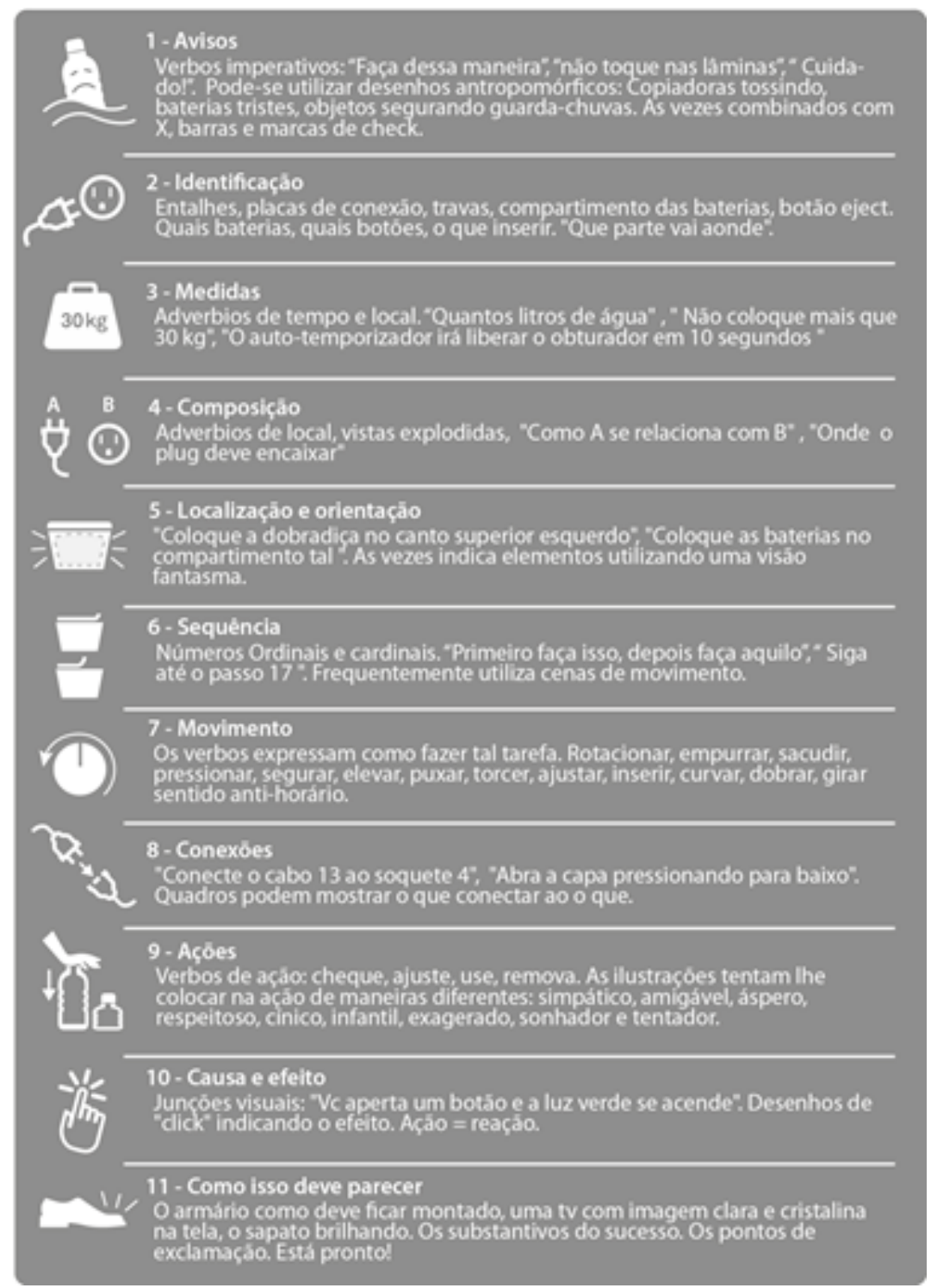

Fonte: baseada em Mijksenaar e Westendorp (1999, p. 56-139)

A abordagem proposta por Mijksenaar e Westendorp foi desenvolvida para ser aplicada em produtos de forma geral, sendo que nem todos os produtos e embalagens necessitam seguir todos 
os onze passos. Entretanto, a apresentação de um produto (ou embalagens), por mais comum e reconhecido que ele seja, deve ser feita de forma clara, garantindo que qualquer usuário possa utilizar e entender aquele produto, conforme argumentam os autores:

Produtos nunca irão falar por si só. Alguém terá que nos ensinar que uma cadeira é para sentar em cima, que uma colher é para colocar comida na boca. Utilizar essas coisas parece intuitivo porque aprendemos sobre elas desde a infância. Mas imagine ver um pedaço achatado de madeira curva com cantos arredondados pela primeira vez. Você saberia dizer para que um bumerangue serve? E como utilizá-lo? Alguém que nunca tinha visto um garfo antes entenderia que aquilo é utilizado para comer? (MIJKSENAAR; WESTENDORP, 1999, p. 13).

A lista de onze elementos engenhosos, proposta por Mijksenaar e Westendorp, aplicados a um projeto de embalagem, visa ampliar possibilidades que o usuário tenha, de forma clara e objetiva, todas as informações necessárias para se relacionar adequadamente com sua utilização. A Figura 4 abaixo apresenta exemplos de embalagens que o uso intuitivo foi facilitado.

Figura 4 - Embalagens intuitivas

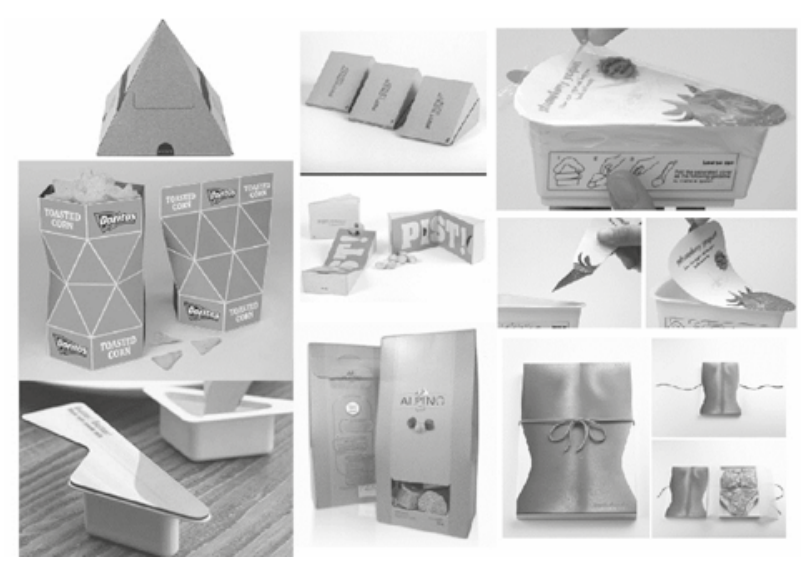

Fonte: arquivo pessoal, baseada em sites diversos 
As embalagens apresentadas anteriormente exemplificam algumas possibilidades do direcionamento para um uso intuitivo devido ao formato, linhas, cores e materiais. Observando o painel, percebe-se a utilização de elementos que sugerem ações, tais como: abas são para puxar, vincos para dobrar, linhas tracejadas para romper e laços para desatar.

\section{SUSTENTABILIDADE}

Para este projeto, sustentabilidade engloba critérios ambientais envolvidos no ciclo de vida de um produto. A autora Wendy Jadlicka, em seu livro Packaging Sustability: Tools, Systems and Strategies for Innovation Package Design, argumenta que as pessoas costumam enxergar as coisas que as rodeiam da mesma maneira linear que é a sua existência: nascimento, vida e morte.

\footnotetext{
As coisas são fabricadas, nós utilizamos e depois jogamos fora. Mas não existe este "fora". Produtos e embalagens têm vida após serem utilizados, seja como lixo (depósitos de lixo ou incineração), ou seja como parte de um novo objeto (reciclados ou reutilizados). Quando objetos renascem (reciclados ou recuperados) e são colocados novamente no sistema, isso se torna um consumo circular que imita a natureza: criar, usar e recriar sem limitações (JADLICKA, 2008, p. 2, tradução livre).
}

Os autores McDonough e Braungart (em seu livro 'Cradle to Cradle-criar e recriar ilimitadamente') compartilham desse pensamento ao abordar o tema ecoeficiência; os autores defendem a necessidade de uma mudança global de pensamento do atual 'do berço à cova' (tradução do termo cradle to grave usado para designar um ciclo de vida linear de produto chegando a um 'fim'), para a concepção ideal do berço ao berço (tradução do termo cradle 
to cradle, que designa produtos criados para serem realocados novamente na cadeia produtiva ou na cadeia orgânica).

\begin{abstract}
Os projetos do modelo cradle to grave dominam a fabricação moderna. De acordo com algumas estimativas, nos Estados Unidos, mais de $90 \%$ dos materiais extraídos para a elaboração de bens duráveis transformam-se lixo quase que imediatamente (MCDONOUGH; BRAUNGART, 2013, p. 34).
\end{abstract}

Para este projeto de embalagem, o tema sustentabilidade visa categorizar problemas ambientais percebidos, que devem ser considerados para minimizar o impacto ambiental provocado pelas embalagens e tornar o produto o mais sustentável possível dentro da realidade da Itálica.

Critérios ambientais ao longo da história vêm evoluindo e se adequando para suprir as necessidades existentes. Segundo Zavadil e Silva (2013, p. 41), a fórmula conhecida como os 3 Rs (Reduzir, Reutilizar e Reciclar) foi atualizada para os 5 Rs (Restaurar, Respeitar, Reduzir, Reutilizar e Recuperar), em que o termo 'Reciclar' deu lugar para o termo'Recuperar', pois “[...] a reciclagem sem reaproveitamento dos recursos materiais e energéticos ainda é apenas um resíduo."

Jadlicka (2008) apresenta as metas de redução de impacto ambiental $7 \mathrm{Rs}$, propostas pela rede WalMart (rede americana de supermercados). Essa proposta pode ser considerada como uma evolução do método dos 5 Rs, tendo o objetivo de se adequar a novos hábitos e envolver seus fornecedores. A autora prossegue argumentando que, "como muitas outras ideias sustentáveis em uso atualmente, o sistema de 7 Rs da WalMart são metas que continuam mudando e melhorando continuamente" (JADLICKA, p. 204). Zavadil e Silva também discutem o sistema adotado: 
Nos últimos anos, a multinacional do varejo WalMart vem investindo em programas de sustentabilidade na sua política interna e com fornecedores, incluindo ações para a redução do impacto ambiental das embalagens. Assim, para atingir as suas metas de sustentabilidade, a rede WalMart estabeleceu 7 Rs a serem considerados por seus fornecedores no desenvolvimento e uso de suas embalagens (ZAVADIL; SILVA, 2013, p. 41).

Para ajudar a rede WalMart a atingir sua meta proposta pelo sistema 7 Rs, os fornecedores devem considerar as sete regras apresentadas na Figura 5 a seguir:

Figura 5 - Metas sustentáveis proposta pelo sistema 7 Rs

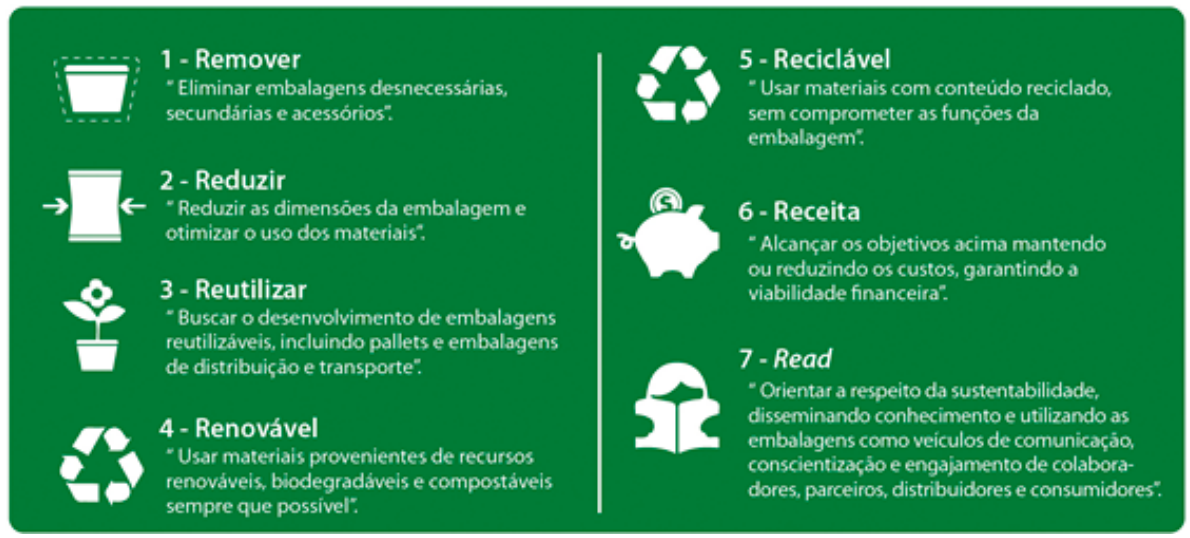

Fonte: baseada em Zavadil e Silva (2013, p. 41)

A escolha e aplicação dos 7 Rs neste projeto, conforme esquema utilizado pela empresa WalMart, se dá porque esse método, além de definir metas a respeito de critérios ambientais como remover, reduzir, reutilizar, renovar e reciclar, define também as metas "receita"e "read", que dizem respeito às questões de âmbito econômico (viabilidade financeira) e social (educação por meio da embalagem), itens que são de interesse da indústria Itálica e do Programa de Mestrado em Design. Além das citadas metas, também é possível reduzir o 
impacto ambiental de uma embalagem, restringindo o uso de tinta na sua rotulagem ou utilizando tintas também com característica biodegradável. A Figura 6 abaixo apresenta embalagens que utilizam materiais sustentáveis em sua composição, como fibras e cascas, e traz exemplos de embalagem biodegradáveis, que reduzem significativamente o impacto ambiental gerado por resíduos de embalagens.

Figura 6 - Embalagens sustentáveis
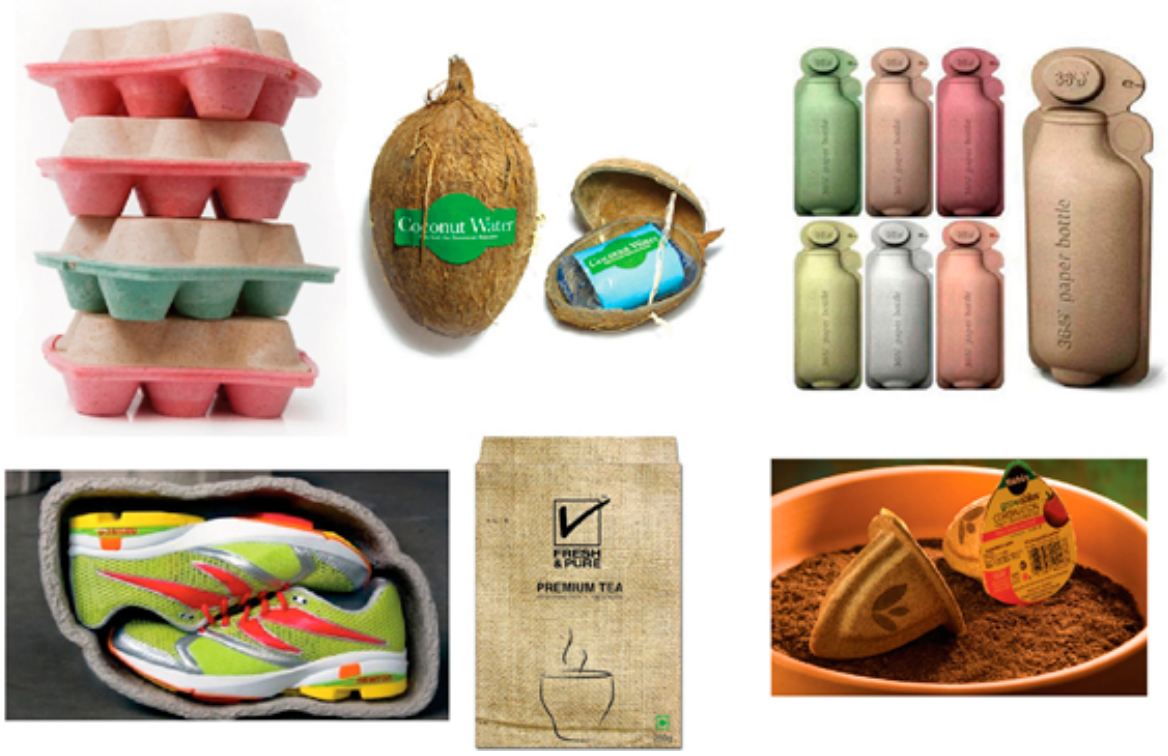

Fonte: arquivo pessoal, baseado em sites diversos

Considerando um projeto de embalagens, além da remoção e redução de elementos secundários e desnecessários, do uso de materiais sustentáveis e da orientação quanto ao descarte correto, o reúso caracteriza uma solução relevante na diminuição do impacto ambiental gerado pelos resíduos das embalagens.

Porém, para facilitar o reúso, os produtos devem ser projetados e fabricados no intuito de viabilizar essas metas, como, por 
exemplo,facilitar a desmontagem. Com essa mesma intenção, Manzini e Vezzoli (2011, p. 201) afirmam que "as alterações necessárias para promover a reutilização devem ser poucas e limitar-se, por exemplo, à limpeza ou à desmontagem e recondução de alguns componentes para os novos produtos".

Para facilitar o reúso dos produtos, Manzini e Vezzoli (2011) listam sete indicações, apresentadas na Figura 7 a seguir.

Figura 7 - Indicações para facilitar o reúso

\section{Indicações para facilitar o reuso}

"Incrementar a resistência das partes

mais sujeitas a avarias e rupturas"

\section{" Predispor o acesso para facilitar a}

$2 \mid$ remoçāo das partes e componentes que podem ser reutilizados"

3 | Projetar partes e componentes | intercambiáveis e modulares "
$4 \mid$ "Projetar partes e componentes estandardizados"

$5 \mid$ "Projetar a reutilizaçāo de partes auxiliares"

$6 \mid$ "Projetar a possibilidade de recarga e/ou reutilização das embalagens"

7 | Projetar prevendo um segundo uso

Fonte: baseada em Manzini e Vezzoli (2011, p. 201)

As sete indicações vistas na Figura 7, dizem respeito a produtos de uma maneira geral; considerando embalagens, podemos explorar algumas indicações como: incrementar a resistência das partes mais sujeitas a rupturas, projetar a possibilidade de recarga ou reutilização das embalagens e projetar prevendo um segundo uso.

\section{METODOLOGIA}

A natureza deste projeto se caracteriza como pesquisa aplicada que, de acordo com Silva e Menezes (2005, p. 14), "objetiva gerar conhecimentos aplicáveis à prática e dirigidos à solução de 
problemas específicos". Considerando que o objetivo é propor uma solução de design para as embalagens das linhas de produtos Itálica (integrando o estudo das relações do design com realidade social, comportamento e o desenvolvimento de produtos sustentáveis que caracterizam a linha de pesquisa 'Produção do design e contexto sociocultural'), sua base técnico-científica apoia-se em teorias, métodos e procedimentos relacionados a relações de uso, design da informação e sustentabilidade.

De modo geral todas as metodologias de design são orientadas para solução de problemas, mas por se tratar de um relatório técnico, e no intuito de estabelecer uma conexão entre o processo de design, os procedimentos de pesquisa, optou-se por subdividir o processo metodológico em macro e microestruturas, contribuindo para a organização lógica dos procedimentos e do relato. Segundo De Brito (2004), os métodos de desenho têm sido entendido como a sequência alternada de dois processos elementares: a macroestrutura e a microestrutura.

Por macroestrutura entende-se a subdivisão do processo de desenho em etapas ou fases, estas dão orientação no procedimento do método. Por microestrutura se entende a descrição das especificações técnicas empregadas em cada uma das etapas ou fases, sendo que estas microestruturas oferecem técnicas e métodos que podem ser utilizados em certas etapas (DE BRITO, 2004, p. 37).

Outromotivo quejustificaesse desdobramentoéa customização do conjunto de procedimentos (microestrutura) associados a cada fase macroestrutural. Essa customização foi derivada das abordagens pretendidas (relações de uso, design da informação e sustentabilidade) e pode ser útil em projetos com enfoques similares. Destaca-se ainda que ao longo do relato o termo fase refere-se aos tópicos da macroestrutura enquanto o termo etapa reporta ao 
conjunto de procedimentos que compõem a microestrutura (cada fase poderá ter mais do que uma etapa).

\section{MACROESTRUTURA}

Para delinear a macroestrutura fez-se uma análise comparativa das estruturas propostas pelos autores Bonsiepe (1984, 2010), Bürdek (2010), De Brito (2004), Löbach (2001), Mestriner (2001, 2002), Meurer e Szabluk (2008) e Tennyson e Alt (2011). Nessa seleção procurou-se buscar autores de abordagens clássicas e contemporâneas.

Com o objetivo de integrar fases e etapas de abordagens clássicas e contemporâneas, da intersecção universidade-empresa desta investigação, da natureza do mestrado em Design da Univille que se caracteriza como profissional, e da intenção de inserir ferramentas e técnicas associadas ao design centrado em usuários ${ }^{2}$, inclui-se, na análise comparativa, estruturas propostas pelas empresas de design IDEO (HCD Toolkit) e Frog Design (Collective Action Toolkit). A Figura 8 permite a visualização das similaridades e divergências dos processos metodológicos de cada autor selecionado. As cores usadas sinalizam a subdivisão das macrofases de desenvolvimento de produto; no primeiro nível de agrupamento (em rosa) estão as fases associadas ao levantamento de informações; no segundo nível (em amarelo) constam fases relacionadas ao planejamento; no terceiro nível (em verde) estão sinalizadas as fases de projeto e de geração de alternativas; no quarto nível de agrupamento (em azul) está marcada a única fase associada a implementação do projeto

\footnotetext{
2 Optou-se por abordagens qualitativas e imersivas mais próximas do design centrado no usuário e ao design participativo (como o HCD Toolkit e Collective Action Toolkit) ao invés do design thinking devido à ênfase deste relatório em aspectos relacionados ao uso. Apesar dessa escolha, reconhecemos que há pontos de conexão entre as abordagens.
} 
(oriunda de Mestriner, cuja abordagem metodológica é voltada para o desenvolvimento de embalagens).

Figura 8 - Macroestruturas, com base em vários autores

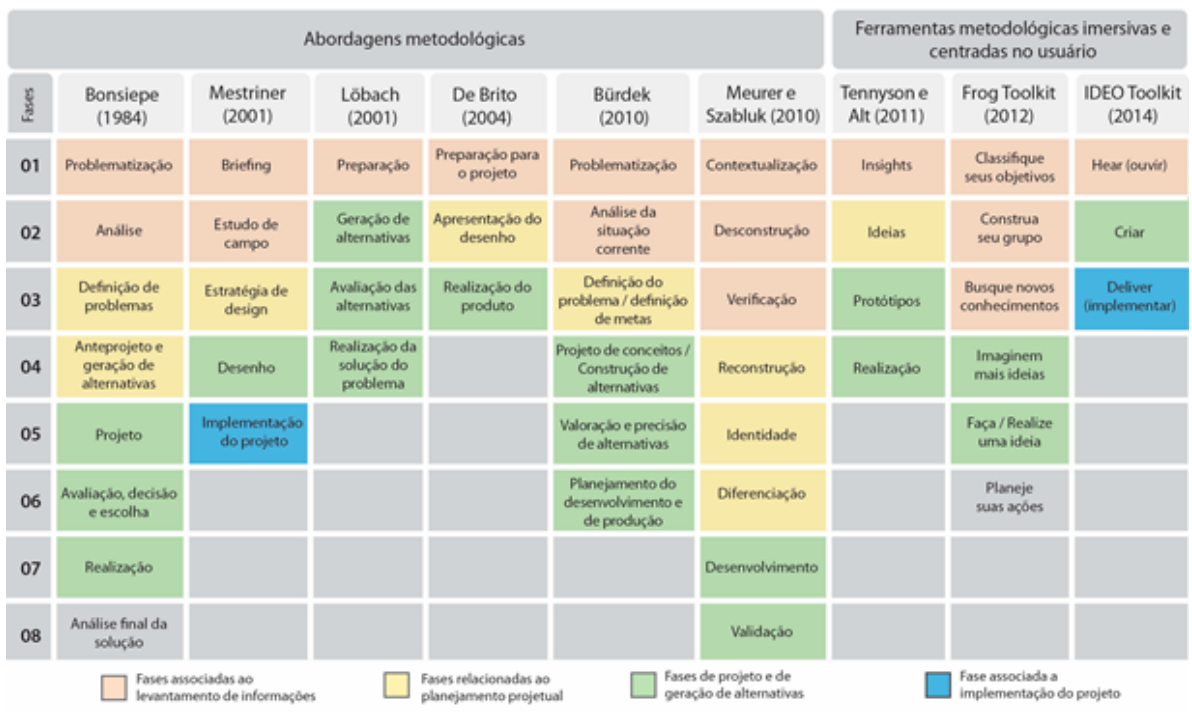

Fonte: arquivo pessoal

Ressalta-se que há uma grande variação quanto ao número de fases sugeridas por cada autor, o que leva à inferência que, em maior ou menor grau, essas fases são desdobradas em microestruturas. Percebe-se, ainda, que algumas fases, apresentadas pelos autores, podem ser incluídas com procedimentos associados a etapas das microestruturas. Essa análise comparativa originou uma síntese, uma formulação de uma macroestrutura própria para este projeto, possibilitando a inclusão de etapas cujos procedimentos estão associados a relações de uso, design da informação e sustentabilidade.

Optou-se pelas fases 'Preparação' (Lobach e De Brito),'Estratégia de Design' (Mestriner), 'Projeto' (Bonsiepe e Burdek), 'Refinamento e Finalização' (Mestriner). Essas fases têm cadência lógica, sugerem 
uma abordagem progressiva e, ao mesmo tempo, possibilitam seu desdobramento em microestruturas cuja seleção de ferramentas possibilita mais flexibilidade. Paralelamente são nomenclaturas próximas ao cotidiano profissional do autor do relatório que atua na área de embalagens, possibilitando uma integração entre sua prática e este estudo técnico-científico. Ao associar essas análises aos objetivos deste projeto, configurou-se a macroestrutura apresentada na Figura 9:

Figura 9 - Caracterização da macroestrutura

\begin{tabular}{|c|c|c|}
\hline $\begin{array}{l}\text { Fases } \\
\text { macro }\end{array}$ & Nomenclatura & Caracteristica \\
\hline 01 & Preparação & $\begin{array}{l}\text { Esta fase engloba as etapas de Diagnóstico e de Análise de Embalagens } \\
\text { Considerando Relaçóes de Uso, Design da Informaçáo e } \\
\text { Sustentabilidade. Para a nomeação foram utilizados os referenciais de } \\
\text { Löbach (2001) e De Brito (2004); com conceitos de Bonsiepe (1984), } \\
\text { Mestriner (2001), Bürdek (2010), Meurer e Szabluk (2010) e Tennyson e Alt } \\
\text { (2011). Foram utilizadas também técnicas e ferramentas utilizadas por } \\
\text { Frog Toolkit e IDEO ToolKit. }\end{array}$ \\
\hline 02 & $\begin{array}{l}\text { Estratégia de } \\
\text { Design }\end{array}$ & $\begin{array}{l}\text { Esta fase engloba as etapas de Estruturação do Problema, Definição e } \\
\text { Hierarquizaçáo dos Requisitos, Modelagem Verbal e Visual do Conceito e } \\
\text { é feito a escolha de um representante de cada linha de produto para a } \\
\text { aplicaçăo do conceito. Para a nomeaçáo é utilizado como referencial a } \\
\text { classificação de Mestriner (2001), sintetizando as fases de definiçăo do } \\
\text { problema e criaçăo de conceito, dos autores Bonsiepe (1984), De Brito } \\
\text { (2004), Bürdek (2010), Meurer e Szabluk (2010) e Tennysone Alt (2011) }\end{array}$ \\
\hline 03 & Projeto & $\begin{array}{l}\text { Esta fase engloba as etapas de Processo de Criação e Desenvolvimento, } \\
\text { Modelagem Fisica das Embalagens para Avaliaçáo e Refinamento e } \\
\text { Validação das Alternativas. Para a nomenclatura é utilizada a classificação } \\
\text { de Bonsiepe (1984), agregando etapas utilizadas por Mestriner (2001), } \\
\text { Löbach (2001), De Brito (2004), Bürdek (2010) e Tennyson e Alt (2011). } \\
\text { Foram aplicadas ainda técnicas utilizadas pelas ferramentas Frog Toolkit } \\
\text { e IDEO ToolKit. }\end{array}$ \\
\hline 04 & $\begin{array}{l}\text { Refinamento } \\
\text { e finalização }\end{array}$ & $\begin{array}{l}\text { Esta fase engloba as etapas de Revisão das Alternativas Finais e de Desdo- } \\
\text { bramentos Projetuais. Como referenciais foram utilizados os métodos } \\
\text { de Mestriner (2001) e da ferramenta IDEO ToolKit. }\end{array}$ \\
\hline
\end{tabular}

Fonte: arquivo pessoal 
Embora não se reconheça, na macroestrutura apresentada na Figura 9, nenhuma fase associada à sustentabilidade, ao Design da Informação ou às relações de uso, as etapas que compõem as microestruturas (detalhadas no próximo tópico) absorveram técnicas e procedimentos com esse enfoque.

\section{MICROESTRUTURA}

Com as macroestruturas definidas, passou-se a delinear as etapas microestruturais de cada fase.

A fase da Preparação é composta por duas microestruturas: Diagnóstico e Análise de Embalagens Considerando Relações de Uso, Design da Informação e Sustentabilidade. A etapa do Diagnóstico inclui o levantamento de informações sobre os produtos Itálica, o estudo do ciclo de vida dos produtos e embalagens da indústria Itálica, o levantamento de necessidades de design com o cliente, a identificação das categorias de usuários, a experiência preliminar de uso dos produtos pelos autores do estudo, a condução de experiências de uso dos produtos com diferentes perfis de usuários, a identificação das percepções dos usuários selecionados para a experiência de uso e a observação da rotina de atividades do usuário interno/funcionário da indústria Itálica. A etapa da Análise de Embalagens considerando Relações de Uso, Design da Informação e Sustentabilidade engloba análises de embalagens de alimentos congelados artesanais, de embalagens de alimentos congelados industrializados, de embalagens com soluções relevantes e de embalagens dos produtos Itálica.

A fase da Estratégia de Design é composta pelas microestruturas estruturação do problema, definição e hierarquização dos requisitos, modelagem verbal do conceito, modelagem visual do conceito 
e escolha de um representante de cada linha de produto para a aplicação do conceito. Na etapa da Estruturação do Problema realizase uma síntese das informações obtidas nas análises anteriores e o problema é redefinido evidenciando requisitos a serem atendidos nas novas embalagens durante a etapa de desenvolvimento, para então na etapa seguinte ocorrer a Definição e Hierarquização dos Requisitos. Na sequência estão situadas as etapas Modelagem Verbal do Conceito e Modelagem Visual do Conceito, para então ocorrer a etapa de Escolha de um Representante de cada linha de Produto para a Aplicação do Conceito gerado.

A fase de Projeto inicia com a etapa de Processo de Criação e Desenvolvimento, na qual estão incluídos procedimentos como processo de criação e desenvolvimento da embalagem física, avaliação e escolha da alternativa das embalagens físicas para as três linhas de produtos, desenvolvimento do projeto de design gráfico e design da informação das três linhas de produtos Itálica. A próxima etapa dessa fase é Modelagem Física das Embalagens para Avaliação e Refinamento constituída por: prototipagem das alternativas finais (testes e modelos de baixa complexidade), refinamento do design gráfico e finalização da alternativa das embalagens propostas para as três linhas de produtos Itálica. Essa fase finaliza com a etapa Validação das Alternativas, constituída por processo de validação com os participantes da experiência de uso das embalagens e processo de validação da solução com o cliente.

A fase de Refinamento e Finalização abrange as etapas microestruturais Revisão das Alternativas Finais e Desdobramentos Projetuais. Na etapa inicial é realizada a revisão das alternativas finais, em que são feitos ajustes e adequações (caso sejam necessários) resultantes da fase anterior. Após essa etapa são realizados os desdobramentos projetuais, em que são sugeridas e discutidas as 
possibilidades futuras em relação às propostas desenvolvidas no projeto.

\section{DESENVOLVIMENTO DA EMBALAGEM}

Após a definição das alternativas, partiu-se para o desenvolvimento do layout dos rótulos das embalagens, definindo cores e elementos visuais do representante de cada linha de embalagem. Nesse momento, além dos requisitos já trabalhados na geração de alternativas, foram inseridos os requisitos legais e de posicionamento da empresa.

Para o desenvolvimento e definição do projeto gráfico dos produtos Itálica, foi escolhida a embalagem da linha Direto ao Forno, que constituiu-se como referência para a aplicação em todas as linhas de produtos Itálica, dentro das suas adequações.

O processo criativo teve início com a definição dos temas centrais Artesanal, Alimento Saudável e Itália, e a partir desses temas foram criadas paletas de cores para que posteriormente fosse definido o padrão cromático do projeto. A Figura 10 apresenta as paletas criadas.

Figura 10 - Paleta de cores por temas

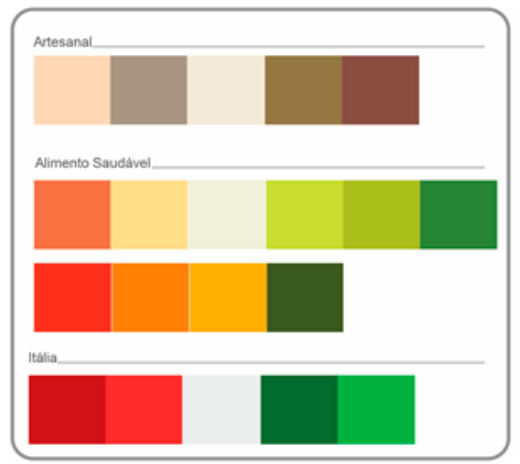

Fonte: arquivo pessoal 
Com as possíveis cores definidas, conforme figura 11 , foram realizados testes cromáticos para definir a combinação de cores utilizadas.

Figura 11 - Definição das cores

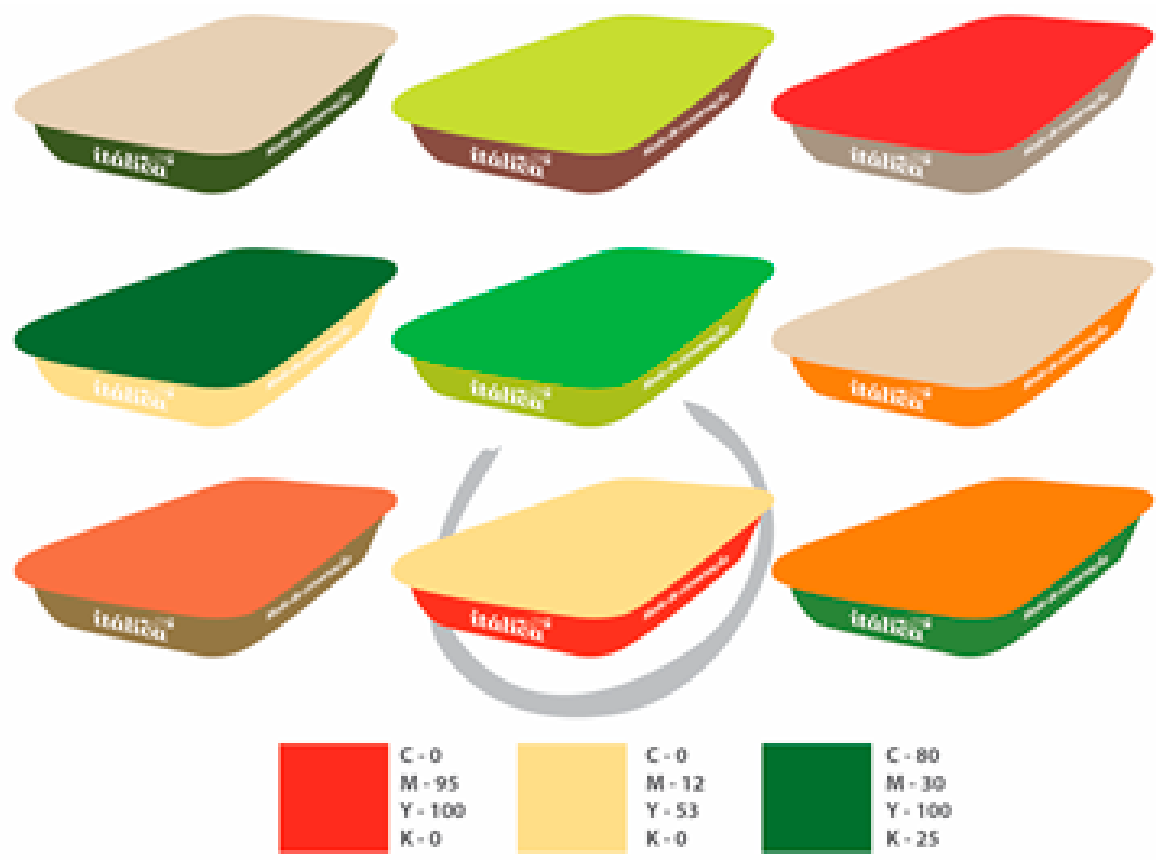

Fonte: arquivo pessoal

Considerando os padrões cromáticos observados em produtos concorrentes e objetivando criar uma combinação que desperte a atenção no ponto de venda, represente o conceito de produto artesanal e mantenha um referencial de reconhecimento da identidade visual atual da Itálica (cor vermelha), foi escolhida a combinação cromática destacada na Figura 11, em que definiu-se uma cor forte para a base (vermelho) e uma cor em tons pastéis para a tampa, associada ao verde que remete a um produto saudável e artesanal. 
Como definido nos requisitos, as embalagens compostas por embalagem termoformada serão impressas em uma cor, para esse caso a cor vermelha apresentada na Figura 11 com código.

Após realizado o estudo de cores, foi feita a estrutura informacional da embalagem, em que foi definido o posicionamento dos elementos gráficos que compõem a embalagem (Figura 12).

Figura 12 - Estrutura informacional da embalagem
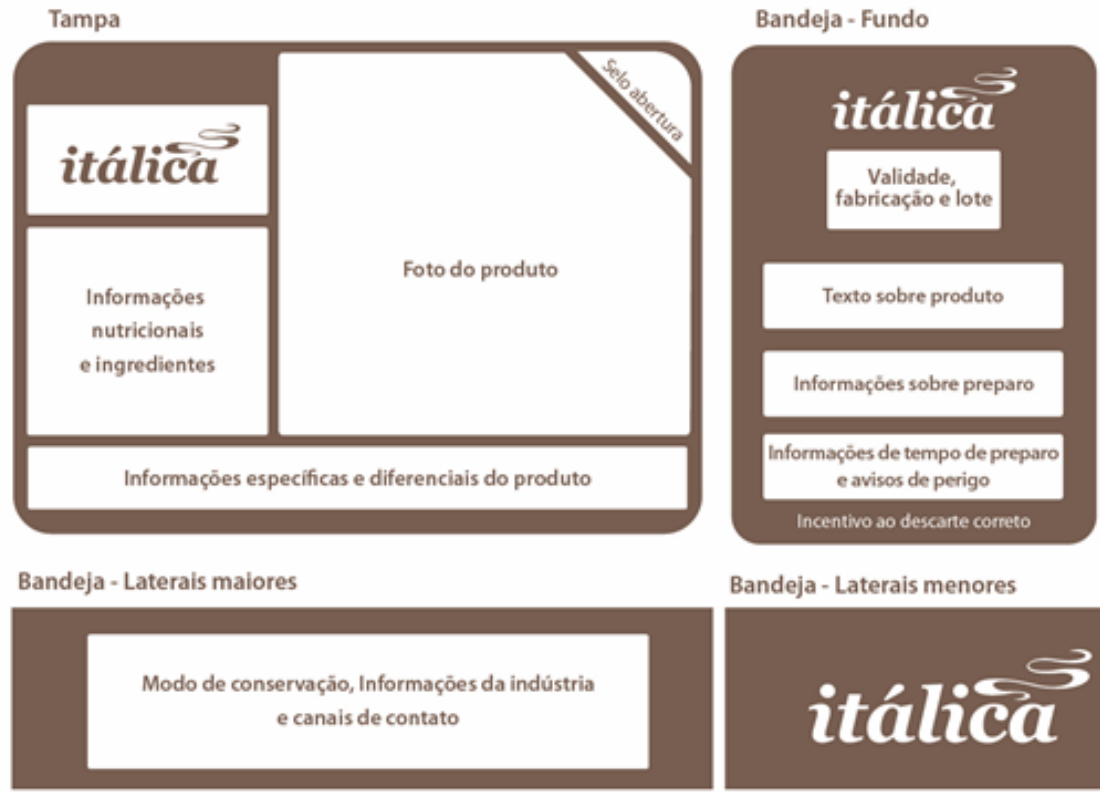

Bandeja - Laterais menores

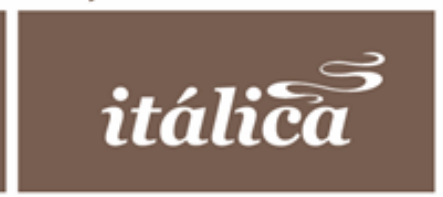

Fonte: arquivo pessoal

A fim de testar a aplicação da nova proposta de design gráfico, foi realizado uma prototipagem rápida em papel da embalagem da linha Direto ao Forno (Figura 13). 
Figura 13 - Prototipagem do layout da linha Direto ao Forno

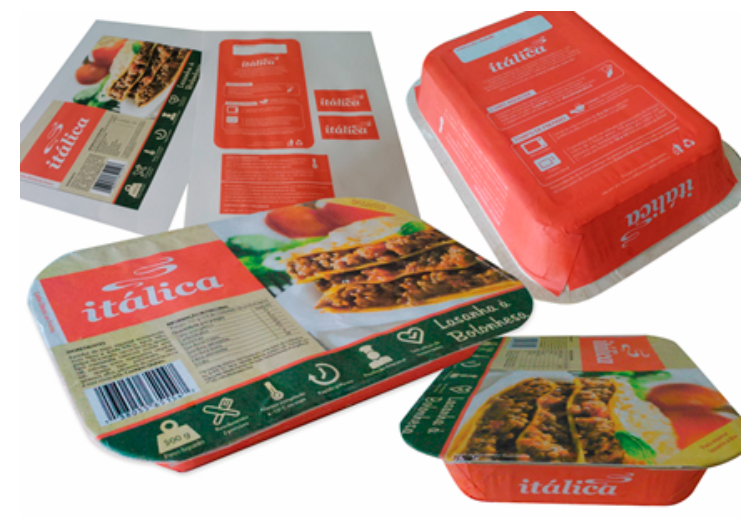

Fonte: arquivo pessoal

EsSa prototipagem teve a função de testar e ajustar a disposição dos elementos e a legibilidade dos textos. Após os ajustes realizados, conclui-se a etapa de criação, sendo definido a nova proposta de design gráfico geral dos produtos Itálica, que será aplicada às demais linhas. Por fim, com o objetivo de representar de forma mais próxima do real, foram gerados simulações de alta definição das alternativas finais. A Figura 14 apresenta a simulação da vista superior (tampa em perspectiva) da linha Direto ao Forno.

Figura 14 - Simulação da tampa da linha Direto ao Forno

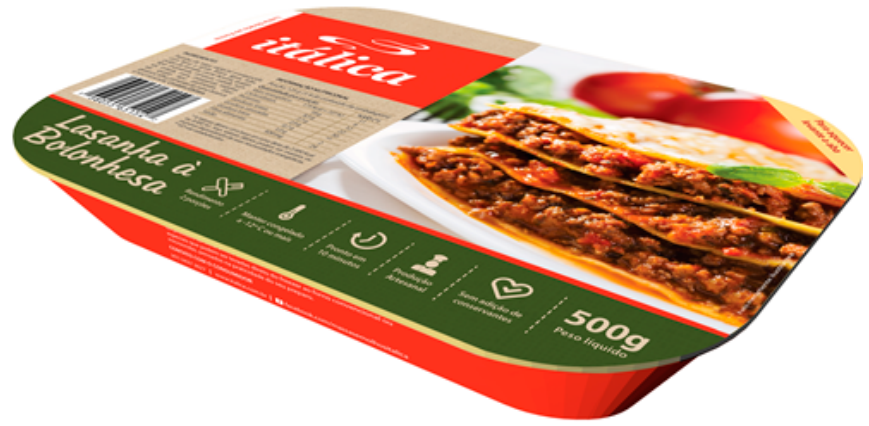

Fonte: arquivo pessoal 
A figura 15 apresenta a simulação da bandeja em perspectiva da linha Direto ao Forno.

Figura 15 - Simulação da bandeja da linha Direto ao Forno

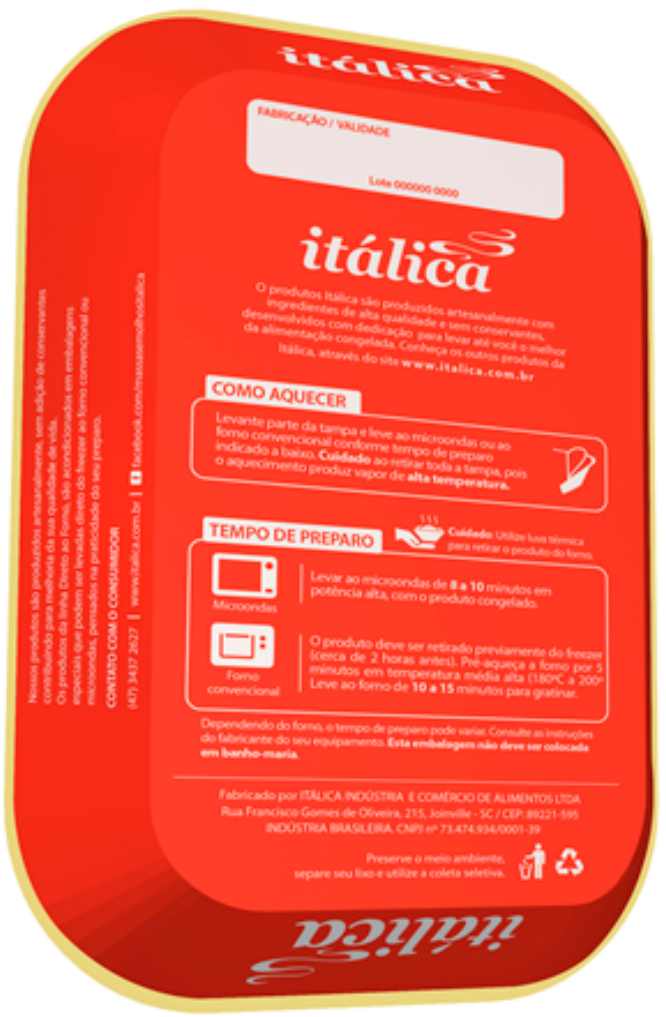

Fonte: arquivo pessoal

A validação com usuários se deu com os oito participantes da experiência de uso das embalagens Itálica. Por conta da dificuldade de reunir os oito participantes, as avaliações de cinco dos participantes se deram em dois encontros realizados no dia 18 e 20 de fevereiro de 2015, e o restante foi realizado via e-mail, sendo enviado um resumo das etapas do projeto e as imagens e layouts gerados da nova proposta. A Figura 16, a seguir, apresenta os encontros realizados. 
Figura 16 - Validação das alternativas com usuários

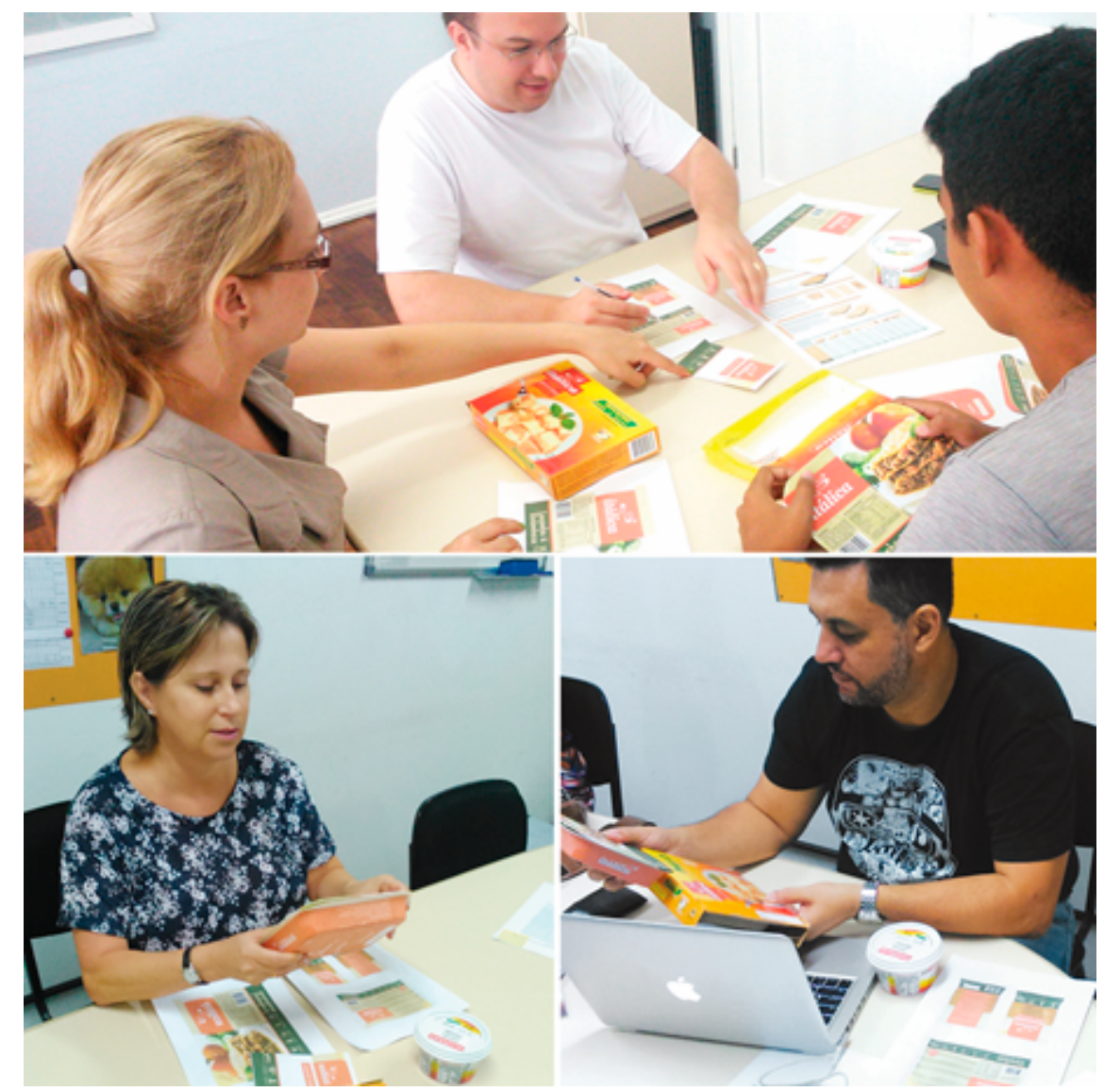

Fonte: arquivo pessoal

\section{CONSIDERAÇOES FINAIS}

As mudanças propostas para as embalagens, além de possibilitarem benefícios para os usuários, poderão gerar uma melhoria no processo interno da indústria itálica no manuseio das embalagens, ganhando tempo ao eliminar as etapas de montagem e fechamento de caixas da linha Direto ao Forno, retirando a 
embalagem secundária; e reduzindo também as etapas de selamento das embalagens da linha Molhos Prontos, ao reduzir o pote (que contém lacre externo e interno) para a embalagem em forma de saco plástico.

Em relação à sustentabilidade, a nova proposta prioriza amenizar a quantidade de resíduos provenientes do uso das embalagens. Sendo que em determinada situação propõe a redução das embalagens excedentes (linha Direto ao Forno), atribui uma nova função para embalagens que têm apenas a função de conter o alimento, prolongando a sua vida útil (bandeja da linha Molho e Forno), e reduz consideravelmente os resíduos plásticos atuais (linha Molho e Forno).

A viabilidade de implementação da proposta foi considerada durante todo o processo de desenvolvimento, entretanto as mudanças propostas devem estar de acordo com o relato e as sugestões feitas pela indústria Itálica, sendo necessário também um estudo mais aprofundado juntamente com os fornecedores, para assegurar que esta nova implementação seja adequada também em termos técnicos e de materiais.

\section{AGRADECIMENTOS}

Agradecimentos ao Programa Institucional de Bolsas de Pós-graduação (PIBPG), ao Fundo de Apoio à Pesquisa (FAP) e à Universidade da Região de Joinville (UNIVILLE) 


\section{REFERÊNCIAS}

. Collective Action Toolkit. Disponível em: <www.frogdesign. com/cat>. Acesso em: 6 mai. 2014.

FROG DESIGN. Disponível em: <www.frogdesign.com>. Acesso em: 5 mai. 2014.

IDEO. Disponível em: <www.ideo.com>. Acesso em: 5 mai. 2014.

IDEO. Human Centered Design Toolkit. Disponível em: <www.ideo. com/work/human-centered-design-toolkit>. Acesso em: 6 mai. 2014.

MIJKSENAAR, P.;WESTENDORP, P. Open Here: the art of instructional design. London: Thames \& Hudson,1999, p. 144.

MORAES, A. M.; MONT'ALVÃO, C. Ergonomia: conceitos e aplicações. Rio de Janeiro: 2AB, 2009, p. 232.

NORMAN, D. O Design do dia a dia. Rio de Janeiro: Rocco, 2006, p. 71.

PREECE, J.; ROGERS, Y.; SHARP, H. Design de interação: além da interação humano-computador. Porto Alegre: Bookman, 2013, p. 600.

SANDERS E. From User-Centered to Participatory Design Approaches. In: Design and the Social Sciences. J.Frascara (Ed.), Taylor \& Francis Books Limited, 2002. Disponível em: http://maketools.com/articlespapers/FromUsercenteredtoParticipatory_Sanders_\%2002.pdf. Acessado em: 15 jun. 2014

TENNYSON, P.; ALT, L. Design Thinking Brasil: empatia, colaboração e experimentação para pessoas, negócios e sociedade. Rio de Janeiro: Elsevier, 2011, p. 230. 
